\title{
ESWEEK 2007 special issue introduction
}

\author{
Reinaldo A. Bergamaschi • Wolfgang Rosenstiel
}

Published online: 18 December 2008

(C) Springer Science+Business Media, LLC 2008

The Embedded Systems Week (ESWEEK) is the premier scientific event in design and implementation of embedded systems hardware, software and tools. ESWEEK brings together three major conferences in the embedded systems area, namely:

- EMSOFT (International Conference on Embedded Software, www.emsoft.org)

- CODES+ISSS (International Conference on Hardware/Software Codesign and System Synthesis, www.codes-isss.org)

- CASES (International Conference on Compilers, Architecture, and Synthesis for Embedded Systems, www.casesconference.org)

ESWEEK 2007 was held in Salzburg with the sponsorship of several professional societies from the ACM (SIGBED, SIGDA, and SIGMICRO) and the IEEE (IEEE Computer Society, IEEE Circuits and Systems Society, and IEEE Council on Electronic Design Automation).

The Program Chairs from the conferences above were invited as Guest Editors of this special issue and asked to select two among the best papers from each conference. Short introductions to their selected papers are given preceding the papers of each conference. We are especially grateful to the Program Chairs for putting together this special issue.

We are proud to publish this collection of best papers from ESWEEK 2007.

Editors-in-Chief

R.A. Bergamaschi $(\bowtie)$

CadComponents Inc., Tarrytown, USA

e-mail: rberga@cadcomponents.com

W. Rosenstiel

Universität Tübingen, Sand 13, Room 119, 72076 Tübingen, Germany 